\title{
Microscopy Underestimates the Prevalence of Trypanosomes' Infection in Asymptomatic Cattle and Sheep in a Lowland Area within the Kenyan Rift Valley
}

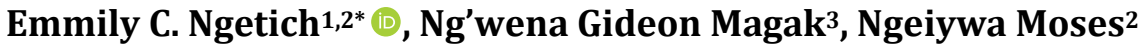 \\ ${ }^{1}$ Department of Biological and Biomedical Sciences, Laikipia University, Nyahururu, Kenya \\ ${ }^{2}$ Department of Biological Sciences, School of Science, University of Eldoret, Eldoret, Kenya \\ ${ }^{3}$ Department of Medical Physiology, School of Medicine, Maseno University, Maseno, Kenya \\ Email: *engetich@laikipia.ac.ke
}

How to cite this paper: Ngetich, E.C., Magak, N.G. and Moses, N. (2019) Microscopy Underestimates the Prevalence of Trypanosomes' Infection in Asymptomatic Cattle and Sheep in a Lowland Area within the Kenyan Rift Valley. Open Journal of Veterinary Medicine, 9, 136-145. https://doi.org/10.4236/ojvm.2019.99012

Received: August 21, 2019

Accepted: September 21, 2019

Published: September 24, 2019

Copyright $\odot 2019$ by author(s) and Scientific Research Publishing Inc. This work is licensed under the Creative Commons Attribution International License (CC BY 4.0).

http://creativecommons.org/licenses/by/4.0/

(c) (i) Open Access

\begin{abstract}
Animal trypanosomosis continues to impede animal production in sub-Saharan Africa mostly in locations where tsetse flies are endemic. This has ended up devastating many livelihoods where majority of the people depend on livestock farming as source of food and income generation. The true picture on prevalence and identity of trypanosome species is scanty or unknown in most areas where tsetse flies are present. This study sought to investigate the prevalence of trypanosomes' infection in cattle and sheep using microscopy and polymerase chain reaction (PCR) methods. The use of PCR for detection and identification of trypanosomes has increased sensitivity of diagnostic method compared to conventional microscopy. Ninety asymptomatic free range grazed animals including 72 cattle and 18 sheep randomly sampled from farmers in Kerio Valley of Elgeyo-Marakwet County, Kenya were used in the present study. Blood samples $(5 \mathrm{ml})$ obtained from each of the animals were used for trypanosomes' detection by microscopy and PCR assay methods. Microscopy results showed that only 2 cattle (2.8\%) were positive for trypanosomosis infection. The microscopy results for the sheep showed zero prevalence. On the other hand, PCR results reported 26 trypanosomosis positive cattle (36.1\%) and 3 (16.7\%) trypanosomosis positive sheep. The PCR method was further used for trypanosomes' species identification and the results showed that the 26 infected cattle were positive for T. congolense (12) and T. brucei (14) while the three sheep were all positive for $T$. brucei. The findings of the present study show that microscopy underestimates trypanosomosis detection and therefore cannot be relied upon as a tool for diagnosis. Besides, the method is
\end{abstract}


weak in reporting species differentiation in a case where the morphological differences have only minor details or where the species are very close morphologically. This study recommends routine use of molecular biology-based technique for trypanosomosis detection in the Kenyan Rift Valley lowland areas.

\section{Keywords}

Kerio Valley, Microscopy, Polymerase Chain Reaction, Trypanosomosis

\section{Introduction}

African Animal Trypanosomosis (AAT) affects livestock production negatively particularly in East Africa where tsetse flies are endemic. Thirty-seven countries within the Sub-Saharan region are affected [1] and it is estimated that $45-50$ million cattle are at risk of trypanosomes' infection in the region with an estimated economic loss of approximately US $\$ 1.3$ billion in cattle production [2]. This problem is complex in the semi-arid areas that face other challenges in animal production including food and water scarcity, insecurity and cattle rustling.

Trypanosomes infecting animals are genetically diverse and are transmitted majorly by tsetse flies. According to Ministry of Livestock Development [3], tsetse flies infest an area covering $138,000 \mathrm{Km}^{2}$ in 38 out of 47 counties in Kenya including Lake Victoria basin, Narok-Kajiado fly belt and Lake Bogoria-Kerio Valley-Turkwel fly belt. The distribution of vector-borne trypanosomosis follows the distribution of Glossina fly. The majority of trypanosomes that cause AAT in East African region include Trypanosoma vivax, T. congolense, T. vivax, T. simiae and T. brucei [3] [4] [5]. Of all the trypanosomes affecting livestock, Trypanosoma congolense and T. vivax have been reported to be the most pathogenic trypanosome to African animals and found most in domestic mammals because of their wide distribution [6] [7]. The Pan African Tsetse and Trypanosomiasis Eradication Campaign (PATTEC) together with Ministry of Livestock Development made a concerted effort to spearhead eradication programmes of trypanosomosis in these endemic areas, a project that ended in 2011 [3].

The mode of diagnosis of haemoparasites that is routinely in use is microscopy through blood smears and many times use of clinical symptoms and signs. Other procedures used in the diagnosis of trypanosomes include serological assays and molecular methods. Although the use of microscopy method in diagnosis of trypanosomes in blood samples remains the primary choice for disease confirmation in the field, it is less sensitive and specific than molecular methods and it is unable to accurately identify parasites in carrier state of infection in animals [8] [9] [10]. Antibody diagnostic methods such Enzyme immunoassay (ELISA), Indirect immunofluorescent antibody tests as much as they are very useful in 
detection of trypanosomes, they are incapable of differentiating past or current infection. Furthermore they are not applicable in the field [1] [11]. Molecular techniques on the other hand offer sensitive and specific tools for the diagnosis of blood-borne infectious diseases and rely primarily on the detection of the causative agent's genome in the blood sample [12]. Field applications of PCR have been used to estimate trypanosome prevalence for the monitoring of control programmes and for detecting very low parasitaemias [5]. Molecular method using PCR-based detection of trypanosome infection in animals therefore can provide information on existence of specific species, prevalence and ultimately epidemiological information on African Animal Trypanosomosis in Kerio Valley.

Previous studies on animal trypanosomosis in Kenya have been carried out mainly in Western part, South of Rift Valley but little information is available for the Kerio Valley where livestock keeping is the mainstay for the communities living in the semi-arid conditions of Kerio valley. Since livestock plays an important role in Kenya's socio-economic development and contributes towards household food and nutritional security especially among the rural communities [13], understanding incidence and prevalence in livestock is paramount in order to undertake effective control measures.

This study was carried out to determine the prevalence of trypanosomiasis in sheep and cattle in Kerio valley using two diagnostic methods, i.e. microscopy and molecular methods using PCR assay. The findings of the present study show that microscopy technique underestimates the detection of trypanosome parasites in cattle and sheep blood and therefore may not be relied upon in the diagnosis of trypanosomiasis.

\section{Materials and Methods}

\subsection{Study Site}

The study was done along the upper Kerio Valley of Elgeyo-Marakwet County, Kenya between June-August 2017. Kerio Valley is situated in a narrow long strip of the Valley land that is approximately $80 \mathrm{~km}$ wide at its broadest, through which the Kerio River flows (Figure 1). It has semi-tropical vegetation on the slopes, while the floor of the valley is covered by dry thorny bush. Annual mean temperatures of $24^{\circ} \mathrm{C}$ is experienced and the rainfall ranges between $1000 \mathrm{~mm}$ to $1400 \mathrm{~mm}$. the study site borders Rimoi National reserve with good vegetation cover, which provides suitable microclimate where tsetse flies can also thrive well. The game reserve consists of large mammalian animals that include elephants, waterbuck, buffalos, bushbuck, and baboons that can serve as parasite reservoir of livestock diseases. Cattle in Kerio Valley region are mostly short-horned East African Zebu breed (Bos indicus) [14], and Red Masai sheep that are grazed extensively on communal land. The main system of grazing in Kerio Valley is free range and at night, the animals are kept in an open animal enclosure close to the homesteads. 


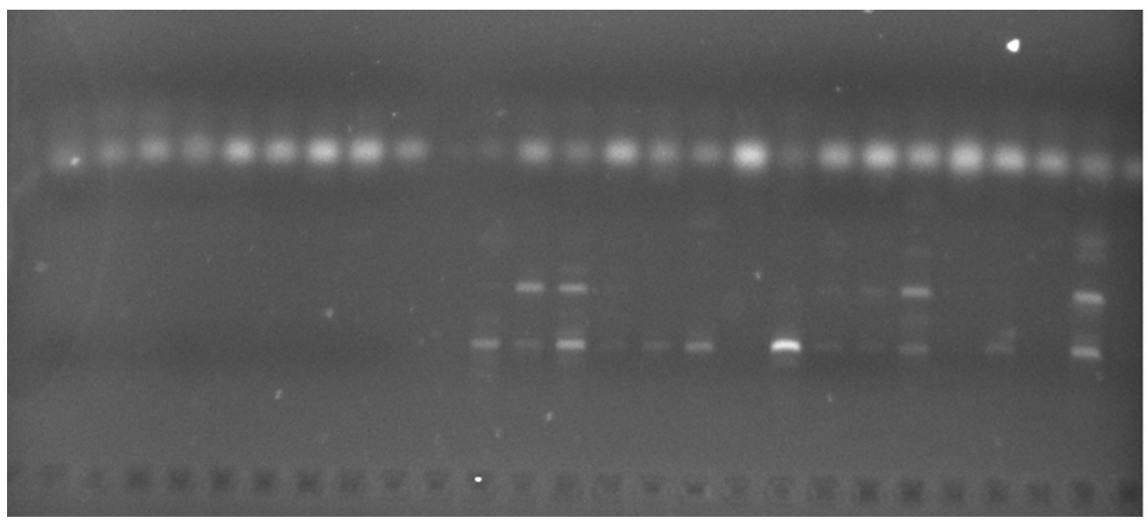

$\begin{array}{lllllllllllllllllllllllll}1 & 2 & 3 & 4 & 5 & 6 & 7 & 8 & 9 & 10 & 11 & 12 & 13 & 14 & 15 & 16 & 17 & 18 & 19 & 20 & 21 & \text { p1 } & \text { p2 } & \text { p3 } & \text { p4 }\end{array}$

Figure 1. Trypanosome DNA bands in agarose gel electrophoresis (2\% TAE).

\subsection{Research Design}

Cross-sectional study design was used involving multistage sampling to select farms and random sampling of the animals was applied. Samples were collected from randomly 3 selected study sites namely Tot, Chesongoch and Chesetah. Blood specimen was taken from every second animal from the order, which they align in a crush. General health conditions, sex and age of sampled animals were recorded against unique identification code by the accompanying animal health officer. The animals ranged from yearlings to adults. The age of the study animals were determined from information given by the owner and the accompanying veterinary officer.

\subsection{Ethical Issues}

Permission to collect samples from the livestock was obtained from the National Commission of Science and Technology and Innovation (NaCoSTI) and from the Research Ethics Committee, University of Eastern Africa, Baraton. The study informed and collaborated throughout the sample collection with Veterinary and Animal Health County office of Elkeyo-Marakwet County. Farmers consent was obtained for the study to be conducted using their animals.

\subsection{Laboratory Procedures}

The blood samples were collected from the jugular vein of the animals, in which the area of the puncture was first cleansed using alcohol swap. Animals of all ages, both males and females were bled using disposable syringes and needles and blood was collected into Ethylene Diamine Tetra-acetic Acid (EDTA) tubes. A drop of blood each was used to prepare thin and thick blood smear in well-labelled slides. The blood smears were air-dried and stored well in slide boxes before transporting to the laboratory. The blood from EDTA tubes was used to make blood spots on labelled Whatman Flinders Technology Associates (FTA) cards (FTA-4 holes-Maidstne, Kent UK). The blood specimen were directly applied to Whatman FTA Cards circles and allowed to air dry prior to 
storage at room temperature using an established method of preservation for sensitive detection of trypanosome infections by PCR following published protocols [15] (Picozzi, 2002).

\subsection{Polymerase Chain Reaction (PCR)}

One $2 \mathrm{~mm}$ punch was cut from the samples on the Whatman FTA Card and DNA extracted according to the manufacturers' instructions (Qiagen, Manchester, UK). Standard PCR cycling was carried out in $29.98 \mathrm{ml}$ reaction mixture containing $2.4 \mu \mathrm{l}$ of $2.5 \mathrm{mM}$ dNTPs in a reaction tube in which $3 \mu \mathrm{l}$ of $10 \mathrm{x}$ buffer was added. $1.08 \mu \mathrm{l}$ of $\mathrm{MgCl}_{2}$ was then added into the mixture, then $1.5 \mu \mathrm{l}$ of Primer 1 (forward) and primer 2 (reverse) respectively was added into the reaction tube. $17.02 \mu \mathrm{l}$ of PCR water was pipetted and added into the mixture. Further, $0.5 \mu \mathrm{l}$ of Tag pol (enzyme) was added and the master mix was vortexed to have a uniform mixture. $30 \mu \mathrm{l}$ of the master mix was measured and was put in labelled amplification tubes. $3 \mu \mathrm{l}$ of the DNA extract was added into the amplification tubes and then loaded into preset thermal cycler and allowed to run under the following conditions:

1) $95^{\circ} \mathrm{C}$ for $7 \mathrm{~min}$ (initial denaturing step),

2) 35 cycles of:

a) Denaturing steps at $94^{\circ} \mathrm{C}$ for $1 \mathrm{~min}$,

b) Annealing at $55^{\circ} \mathrm{C}$ for $1 \mathrm{~min}$,

c) Extension at $72^{\circ} \mathrm{C}$ for $2 \mathrm{~min}$,

3) Elongation at $72^{\circ} \mathrm{C}$ for $7 \mathrm{~min}$,

4) $4^{\circ} \mathrm{C}$ forever.

Parasitaemia were determined by microscopy-based techniques using direct observation of thick and thin blood smear. The thick blood smear was used to determine the presence of the blood parasites in the host, while the thin film was used for full identification of parasite species if present.

\section{Data Analysis}

The data was entered into Excel spreadsheet and exported to STATA 12.0 (Stata Corp, 2012) for analyses. Prevalence rates were determined and compared using appropriate statistics at confidence of $95 \%$. Characterization of trypanosome parasites were dependent on genetic analysis of bands formed by different isolates compared to known profiles. Those that presented identical profiles were considered to belong to the same genotype. The significance limit throughout the data analyses was $p \leq 0.05$.

\section{Results}

The total number of animals investigated was 90 (72 cattle and 18 sheep).

\subsection{Prevalence Using Microscopy}

The use of microscopy showed only $2(2.8 \%)$ of 72 cattle specimens were positive 
for trypanosomes. No trypanosome parasites were detected in blood specimen of sheep by microscopy. Microscopy was not able to distinguish and identify the species of Trypanosoma $s p$ in the blood samples. Trypanosome species and prevalence observed in the study are presented in Tables 1-3.

\subsection{Identification of Trypanosomes Using PCR}

A total of 90 blood samples in FTA cards were analysed for the presence of trypanosomes based on primers specific for different trypanosome species (Table 1).

Table 1. Primers.

\begin{tabular}{|c|c|c|c|}
\hline Primer ID & Sequence & Species & Product Size \\
\hline ITS1 CF & CCG GAA GTT CAC CGA TAT TG & $\begin{array}{l}\text { Trypanozoon; } \\
\text { T. congolense savannah, } \\
\text { T congolense kilifi; } \\
\text { T. congolense forest, } \\
\text { T. vivax }\end{array}$ & $\begin{array}{l}480 ; 700 ; 620 ; \\
700 ; 250\end{array}$ \\
\hline ITS1 BR & TTG CTG CGT TCT TCA ACG AA & & \\
\hline ITS11 & GAT TAC GTC CCT GCC ATT TG & $\begin{array}{l}\text { T. congolense forest, } \\
\text { T. congolense kilifi }\end{array}$ & $1513 ; 1422$ \\
\hline ITS12 & TTG TTC GCT ATC GGT CTT CC & T. congolense savanna & 1413 \\
\hline ITS13 & GGA AGC AAA AGT CGT AAC AAG & $\begin{array}{l}\text { T. brucei s.l. } \\
\text { T. theileri; }\end{array}$ & $1207-1224$ \\
\hline ITS14 & TGT TTT CTT TTC CTC CGC TG & $\begin{array}{l}\text { T. simiae tsavo; } \\
\text { T. simiae; } \\
\text { T. vivax }\end{array}$ & $\begin{array}{l}988 ; 954 ; 850 ; \\
611\end{array}$ \\
\hline
\end{tabular}

Table 2. Prevalence of trypanosome by microscopy and PCR.

\begin{tabular}{cccc}
\hline Diagnostic method & Animal species & No. examined & $\begin{array}{c}\text { Number/percentage } \\
\text { (Positive) }\end{array}$ \\
\hline \multirow{2}{*}{ Total positives by PCR } & Cattle & 72 & $26(36 \%)$ \\
& Sheep & 18 & $3(16.7 \%)$ \\
Total & Cattle & 90 & $29(32.2 \%)$ \\
microscopy & Sheep & 72 & $2(2.8 \%)$ \\
& Total & 90 & 0 \\
\hline
\end{tabular}

Table 3. Prevalence of Trypanosoma sp in cattle and sheep.

\begin{tabular}{ccc}
\hline & T. congolense & T. brucei \\
\hline Cattle $(\mathrm{N}=72)$ & $12(16.7 \%)$ & $14(19.4 \%)$ \\
Sheep $(\mathrm{N}=18)$ & - & $3(16.7 \%)$ \\
\hline
\end{tabular}


Based on the primers for specific Trypanosoma species, the results indicated $29(32 \%)$ out of 90 collected blood samples were positive with trypanosomes (Table 2). Genotype analysis revealed the presence of 14 out of 72 blood specimen of Trypanosoma brucei (19.4\%) and 12 samples of T. congolense (16.7\%) in cattle. Two of the samples positive using microscopy was also captured through molecular method (Figure 1). Three cases out of 18 sheep blood samples $(16.7 \%)$ that initially had not been captured in microscopy were confirmed to be T. brucei.

Trypanosome infection in cattle and sheep are represented in Table 3.

The findings showed that cattle were more likely to be infected with trypanosomes than the sheep (16.7\%). Based on the total number of positive cases, Trypanosoma brucei was the most prevalent (19.4\%) trypanosome found in the livestock in the study area.

\section{Discussion}

Accurate diagnosis and characterization of trypanosomosis is essential in determining the identity and prevalence of Trypanosoma species in livestock, which ultimately inform the development of appropriate control programmes. Although the laboratory technique using microscopy method is commonly applied in the diagnosis of trypanosome infection, it is far from being sensitive or specific. Apart from being time consuming especially when samples are enormous, it requires well-trained laboratory personnel. Contrarily, molecular methods using PCR assays have proven to yield better results, whose process was faster as well as being more sensitive than microscopy. The fact that microscopy only identified $2.2 \%$ positives compared to $32 \%$ through PCR methods showed that microscopy missed $29.2 \%$ positive specimen which were captured by PCR procedures. Using PCR assay method raised the number of infections detected through microscopy from 2 to 29 , which considerably improved our detection of the prevalence and occurrence of trypanosomosis in cattle and sheep. This agrees with previous studies, which showed better diagnosis of Trypanosoma species using molecular methods compared with standard microscopy procedures [16] [17].

Molecular diagnosis indeed, demonstrated that livestock in the study area habour infections caused by trypanosomes consisting of $T$ congolense and $T$ brucei which seem to be the main parasites responsible for African animal trypanosomosis in Kerio Valley. The results showed that T. brucei accounted for significant proportion (19\%) of the trypanosome infection in cattle in Kerio Valley. This finding is contrary to previous reports that $T$. congolense is more prevalent species in cattle in Africa where the infections occur [7] [17] [18]. The identification of trypanosome in sheep confirmed that small ruminants are also readily fed by tsetse flies and are susceptible to trypanosome infection just like bigger ruminants, this agrees with the work done by Masiga and others which reported that small ruminants to be susceptible to trypanosomes infection. Sheep were only found to be infected by $T$. brucei, probably due to chance or possibly de- 
pended on complex epidemiological interactions that vary from one environment to another [19].

The use of PCR identification for trypanosomes has provided an understanding about the prevalence and types of trypanosome infections circulating in livestock and its vectors in Kerio Valley. The difference between prevalence of trypanosomes by microscopy and PCR procedure is undoubtedly due to high sensitivity and accuracy of PCR assay method. The frequency of trypanosome infections in small number of sampled animals was unexpected since Kerio valley is among the areas in which PATTEC-CK project for research and control of the vector and disease had led control programmes since 2005 [3]. This could be due to the fact that most of the animals kept by farmers here are indigenous ze$\mathrm{bu} / \mathrm{sahiwals}$, which are genetically trypanotolerant or possible lapse in stringent control measures after PATTEC project that ended in 2011 [1] [14]. With 29\% and $16.7 \%$ prevalence in sampled cattle and sheep respectively, it confirms the contribution of AAT as one of the causes of looses to the livestock production in Kerio Valley and as such collective efforts by Ministry of Livestock and Development and PATTEC project should be enhanced to control the disease as suggested by previous researchers [8].

\section{Conclusion}

The use of molecular methods for the detection of Trypanosoma $s p$ infections has provided more understanding on its epidemiology due to its sensitivity, specificity and its time-saving feature compared to use of microscopy which is a gold standard. Therefore, PCR method in diagnosis and identification of trypanosomes and other blood protozoan infection is a more valid tool compared to microscopy. Thus, PCR assays are important for diagnosis and early treatment of AAT so as to reduce its morbidity and mortality. This study contributes to the understanding of the existence of African Animal Trypanosomosis (AAT) in the upper Kerio Valley, caused by Trypanosoma brucei and T. congolense, with similar implications in the entire Kerio valley where tsetse fly thrive. The presence of T. congolense in study site poses potential danger to public health because of its capability of being zoonotic. Although the prevalence of trypanosome infection was low, their effect can still manifest in production loses in terms of depressed growth, meat and milk productivity. Molecular method for the diagnosis of animal trypanosomosis is of great importance for treatment and control of the $\mathrm{AAT}$ and very useful tool for rapid and reliable results with high sensitivity and specificity. The use of molecular assays based on PCR method for diagnosis and surveillance of trypanosomosis is highly recommended. The presence of animal trypanosomes in Kerio Valley requires formulation of effective control measures, routine screening and surveillance by PCR that works in tandem with tsetse fly control methods.

\section{Acknowledgements}

We acknowledge support for excellent fieldwork and laboratory work from El- 
geyo-Marakwet county field staff in animal health department. Special thank you to Mr Chemwolo, Victor, Meshack and Koech for technical assistance during laboratory procedures at the university of Eldoret and Maseno. We are grateful to the farmers for their time and cooperation during sampling and the University of Eldoret, Maseno and Laikipia universities for institutional support.

\section{Funding}

National Research Fund-Kenya.

\section{Conflicts of Interest}

The authors declare that they have no conflict of interest.

\section{References}

[1] Thumbi, S., Jung'a, O., Mosi, O. and and McOdimba, F. (2010) Spatial Distribution of African Animal Trypanosomosis in Suba and Teso Districts in Western Kenya. Biomedical Central Research Notes, 3, 6. https://doi.org/10.1186/1756-0500-3-6

[2] Kristjanson, P.M., Swallow, B.M., Rowlands, G.J., Kruska, R.L. and De Leeuw, P.N. (1999) Measuring the Costs of African Animal Trypanosomiasis, the Potential Benefits of Control and Returns to Research. Agricultural Systems, 59, 79-98. https://doi.org/10.1016/S0308-521X(98)00086-9

[3] MoLD (2011) Strategy for Tsetse and Trypanosomiasis Eradication in Kenya 2011-2021. 11-17.

[4] Taylor, K. and Authie', E. (2004) Pathogenesis of Animal Trypanosomosis. CABI Publishing, Wallingford, Oxfordshire, 331-353.

[5] Bronsvoort, B.W. (2010) No Gold Standard Estimation of Sensitivity and Specificity of Two Molecular Diagnostic Protocols for Trypanosoma brucei spp. in Western Kenya. PLoS ONE, 5, e8628. https://doi.org/10.1371/journal.pone.0008628

[6] Majiwa, P.H. (1986) Evidence for Genetic Diversity in Trypanosoma congolense. Parasitology, 93, 291-304. https://doi.org/10.1017/S0031182000051465

[7] Isaac, L.A. (2013) Haematological Properties of Different Breeds and Sexes of Rabbits. 18th Annual Conference of Animal Science Association of Nigeria, Animal Science Association of Nigeria, Nigeria, 24-27.

[8] Ng'wena, G.M., Okoth, W.O., Owiti, G.M., Onyango, K., Owiti, O.T., Awino, B., Oyieko, W., Wandabwa, C.K. and Odero, W. (2019) Human and Animal Trypanosomiasis in Lambwe Valley Foci, Kenya-Current Situation and Latent Trypanotolerance. Asian Journal of Research in Animal and Veterinary Sciences, 3, 1-12

[9] Criado-Fornelio, A., Martinez-Marcos, A., Buling-Sarana, A. and Barba-Carretero, J.C. (2003) Molecular Studies on Babesia, Theileria and Hepatozoon in Southern Europe. Part II. Phylogenetic Analysis and Evolutionary History. Veterinary Parasitology, 114, 173-194. https://doi.org/10.1016/S0304-4017(03)00141-9

[10] Zweygarth, E., Just, M.C. and De Waal, D.T. (1997) In Vitro Cultivation of Babesia equi: Detection of Carrier Animals and Isolation of Parasites. Onderstepoort Journal of Veterinary Research, 64, 51-56.

[11] Nantuly, V.M. (1990) Trypanosomiasis in Domestic Animals: The Problems of Diagnosis. Revue Scientifique et Technique, 9, 357-367.

https://doi.org/10.20506/rst.9.2.507 
[12] Ahmed, A.H., MacLeod, T.E., Hide, G., Welburn, S.C. and Picozzi, K. (2011) The Best Practice for Preparation of Samples from FTA ${ }^{\star}$ Cards for Diagnosis of Blood Borne Infections Using African Trypanosomes as a Model System. Parasites \& Vectors, 4, 68. https://doi.org/10.1186/1756-3305-4-68

[13] Ministry of Livestock-MOLD (2010) Strategic Plan 2008-2012. 1-3.

[14] Rege, J.E.O., Kahi, A., Okomo-Adhiambo, M., Mwacharo, J. and Hanotte, O. (2001) Zebu Cattle of Kenya: Uses, Performance, Farmer Preferences and Measures of Genetic Diversity and Options for Improved Use. ILRI, Kenya, Nairobi, 3-10.

[15] Picozzi, K.T. (2002) The Diagnosis of Trypanosome Infections: Application of Novel Technology for Reducing Disease Risk. African Journal of Biotechnology, 1, 39-45. https://doi.org/10.5897/AJB2002.000-007

[16] Ng’ayo, M.O., Njiru, Z.K., Kenya, E.U., Muluvi, G.M., Osir, E.O. and Masiga D.K. (2005) Detection of Trypanosomes in Small Ruminants and Pigs in Western Kenya: Important Reservoirs in the Epidemiology of Sleeping Sickness? Kinetoplastid Biology and Disease, 4, 5.

[17] Majekodunmi, A.O., Fajinmi, A., Dongkum, C., Picozzi, K., Thrusfield, M.V. and Welburn, S.C. (2013) A Longitudinal Survey of African Animal Trypanosomiasis in Domestic Cattle on the Jos Plateau, Nigeria : Prevalence, Distribution and Risk Factors. Parasites \& Vectors, 6, 239. https://doi.org/10.1186/1756-3305-6-239

[18] Leak, S.G.A. (1999) Tsetse Biology and Ecology: Their Role in the Epidemiology and Control of Trypanosomosis. Elsevier Science Ltd., London.

[19] Masiga, D.K., Okech, G., Irungu, P., Ouma, J., Wekesa, S. and Ouma, B. (2002) Growth and Mortality in Sheep and Goats under High Tsetse Challenge in Kenya. Tropical Animal Health and Production, 34, 489-501. https://doi.org/10.1023/A:1021241220575 http://www.cipav.org.co/TAP/tapindex.htm 